\title{
De uma língua oral sem escrita à escrita de uma língua oral: o caso do crioulo cabo-verdiano das ilhas do Barlavento e Sotavento
}

\section{From an oral language without writing to the writing of an oral language: the case of Cape Verdean Creole from the islands of Barlavento and Sotavento}

Natalia Czopek [morenat@gmail.com]

Uniwersytet Jagielloński, Kraków, Polónia

\section{RESUMO:}

O objetivo principal do nosso trabalho é propor uma descrição dos traços ortográficos, morfossintáticos e lexicais do crioulo das ilhas do Barlavento e Sotavento, realçando os vestígios deixados pela língua portuguesa como resultado de migrações e mestiçagem entre o povo colonizado e o colonizador. O corpus de exemplos será fornecido pela coletânea de histórias Mam Bia tita Contá Estória na Criol, recolhidas pela escritora cabo-verdiana Ivone Aida como um testemunho vivo das tradições orais das ilhas de Santiago e São Nicolau. Pretendemos observar a transformação linguística que sofre o intertexto oral ao ser registado na escrita. Trata-se aqui precisamente de refletir na linguagem escrita a contaminação e a mestiçagem presentes na linguagem oral das sociedades culturalmente hibridas, criando um "amálgama" de vozes.

\section{Palavras-chave:}

Crioulo; Cabo Verde; Barlavento; Sotavento; tradição oral e escrita

\begin{abstract}
:
The main objective of our work is to propose a description of spelling, morphosyntactic and lexical features of the Creole of the Barlavento and Sotavento islands, highlighting the traces left by the Portuguese language as a result of migration and miscegenation between the colonized people and colonizers. The corpus of examples will be provided by the collection of stories Mam Bia tita Contá Estória na Criol collected by a Cape Verdean writer Ivone Aida as a living testimony of oral traditions of the islands of Santiago and São Nicolau. We intend to observe the linguistic transformation suffered by an oral message when recorded in writing and analyze the influence of the contamination and miscegenation, present in the oral tradition of culturally hybrid societies, in the written language, creating an "amalgam" of voices.
\end{abstract}

\section{KEYWORDS:}

Creole, Cape Verde; Barlavento; Sotavento; oral and written tradition

RECEBIDO 2015-06-18; ACEITE 2016-01-30 


\section{Introdução}

O objetivo principal do nosso trabalho é propor uma descrição dos traços ortográficos, morfossintáticos e lexicais do crioulo das ilhas do Barlavento e Sotavento, realçando os vestígios deixados pela língua portuguesa como resultado de migrações e mestiçagem entre o povo colonizado e o colonizador. Preocupa-nos analisar até que ponto os dois sistemas linguísticos diferem e quais podem ser as origens dessas divergências. Tendo em conta o espaço e tempo reduzidos, limitamo-nos a traçar uma imagem geral e aproveitamos um corpus de pequenas dimensões, esperando que este trabalho possa servir de base para um estudo mais desenvolvido.

O corpus de exemplos será fornecido pela coletânea de histórias Mam Bia tita Contá Estória na Criol, recolhidas pela escritora cabo-verdiana Ivone Aida como um testemunho vivo das tradições orais das ilhas de Santiago e São Nicolau.

\section{A importância da tradição oral na cultura dos povos africanos}

A tradição oral tem desempenhado um papel muito importante na cultura dos povos africanos, sendo a fonte primordial da sua história e refletindo os aspetos relevantes da sua vida ${ }^{1}$. A ideia de "continuidade" entre a natureza cultural e a herança oral, radicada nos mestres da palavra, os chamados griots, e a literatura africana foi defendida já pelo grande representante da Negritude, Leopold Senghor ${ }^{2}$. O griot é um especialista escolhido ou por linhagem, ou por profissão, e só ele detém o conhecimento dos textos mais longos e especiais, como a epopeia, as genealogias ou a crónica histórica (Leite 1998: 14-39)³. O seu papel principal é não deixar que

1 Cf. Postioma (1968: s/p): “A palavra no meio africano goza de uma tarefa privilegiada; a palavra que foi pronunciada e produzida pelos antepassados encontra-se hoje como norma doutrinal e moral; ela continua ainda a operar, a instruir, a exortar e a guiar. Em África não falam somente os sábios e os poetas; todos gostam de falar. [...] A palavra é vida, é a expressão da alma, do ser mais profundo, do íntimo do coração. Um homem que não fala é doente ou falecido; falar é mostrar aos outros a própria vida: 'Eu falo logo existo'. [...] A palavra africana é poderosa, dinâmica, porque é um símbolo que permite a uma força entrar em contacto com outro ser”. Cf. também uma citação do $A$ varanda do frangipani de Mia Couto (Manana de Sousa 2009: 140): "Neste asilo o senhor se aumente de muita orelha. É que nós aqui vivemos muito oralmente".

2 Cf. Leite (1998 : 14-39): vejam-se, por exemplo, as considerações de Leopold Senghor acerca da poesia: "Le Nègre singulièrement, qui est d'un monde où la parole se fait spontanément rythme dès que l'homme est ému, rendu à lui même à son authenticité. Oui la parole se fait poème [...]". Alioune Tine afirma que "La littérature africaine se définit comme une littérature située entre l'oralité et l'ecriture. Cette idée a permis la réalisation d'un vaste consensus qui va des critiques africanistes aux écrivains" e A. Irele que "[...] the tradition of orality remains predominant, serving as a central paradigm for various kinds of expression on the continent [...]. In this primary sense, orality functions as the matrix of an African mode of discourse, and where literature is concerned, the griot is its embodiment in every sense of the word. Oral literature thus represents the basic intertext of the African imagination". No entanto, podem-se também encontrar opiniões que a predominância da oralidade em África é resultante de condições materiais e históricas e não da "natureza" africana. Além disso, citam-se duas atitudes extremadas para com a oralidade: a primeira considera as sociedades orais primitivas, não sujeitas a trabalho reflexivo; a segunda considera-as exemplares.

3 Estes factos contrariam a teoria de as tradições orais serem acessíveis a todos e igualitárias enquanto a escrita é mais seletiva. Cf. também Leite (2003: 89): "A arte de narrar oral é um dos aspectos do quotidiano africano. A história é uma espécie de medium à conversa e funciona como exemplum”. Sublinhando a importância das gerações mais velhas na transmissão e conservação da memória do povo, Amadou Hampâté Bâ (Ribeiro s/d: 119) afirmou que "Na África, cada ancião que morre é uma biblioteca que se queima”. Infelizmente, como constatou Pepetela numa das entrevistas, 
toda a bagagem cultural e histórica da tradição oral africana caia em esquecimento e transmitila às gerações posteriores. A ideia é ser fiel à versão recebida do antecessor mas temos de tomar em conta também o chamado "fator humano", isto é, as possíveis mudanças provocadas pelo esquecimento, invenção própria ou influência do idioleto do contador. Somando-se tudo isso à representação ortográfica recém padronizada, ficamos com a imagem mais ou menos completa das dificuldades em refletir, na linguagem escrita, a contaminação e a mestiçagem presentes na linguagem oral das sociedades culturalmente hibridas "através da recriação sintática e lexical e de recombinações linguísticas, provenientes, por vezes, mas nem sempre, de mais do que uma língua”, criando um "amálgama” de vozes 4 . Como exemplo, pode-se comentar o caso da sintaxe normativa modal e temporal portuguesa que se torna semelhante à oralidade africana com, por exemplo, marcas do discurso indireto livre. O narrador assume o papel do velho contador de histórias, aproveitando o modo de narrar solto, circunloquial, simulando a espontaneidade popular e produzindo uma aceleração discursiva (Laranjeira 1995: 121-123). É comum começar e acabar as estórias com as fórmulas mais típicas da tradição oral, por exemplo:

1. Era uma bez $[\ldots](9)^{5}$; Um bez tinha [...] (15); Quem qui sabe más conta midjor [...] $(19,27$, 64); Estória, Estória, Fortuna de Céu, Amém (20).

criando, pelo meio, um ambiente de um encontro à fogueira durante o qual um griot transmite a herança cultural do povo. Outra marca da oralidade é a recuperação de estratégias como provérbios, sentenças, frases feitas e portadoras de significação didático-filosófica (Leite 1998: 44-49). O uso de provérbios e sentenças, formas alegóricas de didatismo e filosofia é muito importante para as culturas africanas, sendo pontes entre a sabedoria dos mais velhos e o mundo moderno ${ }^{6}$ :

\footnotetext{
"as populações saem do interior, perdemos laços tradicionais e a figura daquele mais velho contador de histórias, o griot, desapareceu praticamente. Isto em termos de campo. Encontramos apenas alguns griots suburbanos, mas é uma coisa que está desaparecendo" (Ribeiro s/d: 121).
}

4 Cf. Leite (1998: 33-43): O fenómeno ganhou também o nome de oralização ou tematização linguística, um processo transformativo e nativizante da língua do colonizador no qual "se desvelam as "tradições" traídas, e reformuladas, e se recuperam os traços genealógicos de variadas "formas" ou "géneros" orais africanos, e outros géneros provenientes da literatura escrita". Para esta modelação linguística aplica-se também o termo "fala", seguindo a distinção saussuriana entre langue e parole.

5 Os números indicam as páginas da obra de Ivone Aida Mam Bia tita Contá Estória na Criol.

6 Cf. Leite (2003: 53): Os zulus dizem que sem provérbios “a linguagem é como um esqueleto sem carne ou um corpo sem alma" e os Yoruba que "o provérbio é o cavalo do discurso; se o discurso se perde, usa-se o provérbio para o procurar". Cf. também Ndoleriire (2000: 274): “[...] individual people learn the values, norms, beliefs, views, and behavioural patterns (in other words, the culture) of the group or groups of which they are members through linguistic interaction". A importância dos provérbios fica também confirmada em Postioma (1968: s/p.): "A palavra é o tabernáculo, o cofre da sabedoria africana, cuja principal manifestação são os provérbios frequentemente estudados pelos etnólogos. Os provérbios contêm um real fundamento filosófico sobre os principais problemas humanos; são lições de vida prática; são um quadro onde se encontram escritas as regras e as relações sociais". Não se pode ignorar vozes que defendem que não é possível introduzir o texto oral para a escrita mantendo a mesma força da tradição oral. Citemos as palavras de Manuel Rui (Chaves 2000: 249): “E agora? Vou passar o meu texto oral para a escrita? Não. É que a partir do momento em que eu o transferir para o espaço da folha branca, ele quase morre. Não tem árvores. Não tem ritual. [...] Não tem som. Não tem dança. Não tem braços. Não tem olhos. [...] Como escrever a história, o poema, o provérbio sobre a folha branca? Saltando pura e simplesmente da fala para a escrita e submetendo-me ao rigor do código que a escrita já comporta? Isso não. No texto oral já disse não toco e não o deixo minar pela escrita, arma que eu conquistei ao outro. Não posso matar o meu texto com a arma do outro". 
2. Lá diz o velho ditado: ninguém está contente com a sua sorte (46); Quem tudo quere tudo perde $(22,61)$.

É fundamental que toda esta sabedoria dos antepassados se transmita na língua nacional do povo. Constituindo um dos principais fatores da sua identidade individual e coletiva, esta língua vincula-o, por sua vez, ao nível de costumes e tradições, como se verifica, por exemplo, com o crioulo cabo-verdiano. No entanto, vale a pena realçar, como faz Manuel Veiga (2000: 263), que a escrita é apenas um meio e não um fim; um sistema arbitrário de transferência da linguagem oral, o seu suporte subsidiário.

\section{A herança de migrações e mestiçagem - bilinguismo ou diglossia?}

Um dos problemas que tem interessado muito os linguistas é como designar a realidade linguística de Cabo Verde. Os dois termos - bilinguismo e diglossia - começaram a empregar-se falando do contexto cabo-verdiano a partir da independência, em 1975. O bilinguismo costuma ser definido como a existência de duas línguas com o mesmo estatuto, utilizadas pelos falantes com as mesmas competências e eficácia, em qualquer contexto ou circunstância, sendo ambas prestigiantes e com o mesmo estatuto funcional e social (Veiga 1995: 30). A diglossia, por sua vez, só se aplica quando existem, num indivíduo ou numa comunidade, duas ou mais línguas mas com estatutos socio-políticos diferentes (Delgado 2009: 332).

No arquipélago existe um código de comunicação usado por todos os falantes no seu quotidiano, na variante correspondente a cada ilha, e outro código empregue nas situações formais. O português, designado às vezes como a "língua das coisas impessoais" (Duarte 2003: 116), tem o estatuto de língua oficial, da escrita e da comunicação internacional; o crioulo é a língua da oralidade e de identidade social e cultural. Ao mesmo tempo, o crioulo desempenha a função do primeiro código aprendido pelas crianças, isto é, da sua língua materna e nativa, base da sua identidade, enquanto que, com o português, a criança tem normalmente o primeiro contacto na escola. Atualmente, embora o crioulo seja usado cada vez mais em situações de comunicação formal, a par do português, este continua a ser a língua preferida na ciência e na educação, entrando até, às vezes, no campo da oralidade. Como afirma Almada Duarte (2003: 31), o bilinguismo nas ilhas tem sido um problema de classe: o português sempre foi a língua da pequena burguesia mas a grande massa da população teve um acesso muito restrito à língua do colonizador, o que quer dizer que praticamente não a falava e, sobretudo, não a escrevia. Como efeito, só uma pequena parte da população é realmente bilingue, sendo mais fácil encontrar casos de bilinguismo individual. Portanto, no contexto cabo-verdiano, tomando em consideração a desigualdade das duas línguas, pode falar-se antes de diglossia prevalecente: oral, com vantagem para o crioulo; e escrita, com vantagem para o português (Veiga 1995: 29-31). 


\section{Como escrever uma língua oral? - tentativas de padronização ortográfica dos crioulos cabo-verdianos}

Antes do século XIX, os linguistas dedicavam-se apenas ao estudo das línguas de tradição escrita, considerando as outras como primitivas e inferiores, sem qualquer prestígio social. A grafia do crioulo cabo-verdiano remonta ao século XIX. As primeiras obras linguísticas dedicadas ao crioulo são "Os dialetos românicos ou neo-latinos na África, Ásia e América” de Francisco Adolfo Coelho, de 1880, e "Apontamentos para a gramática do crioulo que se fala na ilha de Santiago" escritos por António de Paula Brito em 1885 e publicados em 1888. Nessa primeira fase da sua evolução, a escrita em crioulo era uma escrita sem regras, baseada sobretudo na etimologia, ou seja, no alfabeto português, com fortes marcas regionalistas, da proveniência do autor. Era a chamada escrita tradicional, pouco sistemática e pouco económica, pois para o mesmo fonema existiam vários grafemas. Nas publicações mencionadas surge uma proposta de introdução de uma grafia com um grafema correspondente, em cada contexto, a um som, mas muitos autores (como Eugénio Tavares ou Sérgio Frusoni) preferiram seguir a escrita etimológica, havendo até casos de hesitações ortográficas dentro da mesma obra. A etapa seguinte marcou-se pela organização do Colóquio do Mindelo, em 1979, durante o qual se discutiram muito as questões ortográficas e do distanciamento da escrita cabo-verdiana da portuguesa ${ }^{7}$. No entanto, a proposta do alfabeto (o chamado "alfabeto do chapéu") adotada no Colóquio e modificada mais tarde, em 1989, no Fórum da Praia $^{8}$, foi rejeitada por se afastar demasiado da escrita etimológica. Em 1993, criou-se um grupo para a padronização do alfabeto que apresentou o ALUPEC (Alfabeto Unificado para a Escrita do Cabo-verdiano), que visava juntar os dois modelos, o etimológico e o fonológico, isto é, a economia e o fator histórico. De acordo com as suas regras, cada som corresponde a um símbolo e todas as letras são de base latina9. Constatou-se também que, no futuro, seria preciso criar dois alfabetos interdialetais para cada grupo de ilhas. O ALUPEC despertou várias controvérsias, por exemplo relativamente à introdução de alguns sons ou às regras de acentuação, mas acabou por ser aprovado, em 2009, mesmo sendo incapaz de encontrar soluções para um país de multiplicidade de variantes. Assim, pode-se concluir que apesar de serem notáveis uma evolução e progresso no sentido de elaboração de um alfabeto cabo-verdiano, ainda não se apresentou nenhuma proposta que satisfaça as exigências gráficas do país inteiro. No entanto, seguindo a opinião de Dulce Almada Duarte (2003: 26-27), este facto não pode ser razão justificativa para o desprezo do crioulo, já que todas as línguas do mundo passaram pela fase de exclusiva oralidade e nem tudo o que é literário é escrito, como nem tudo o que é escrito é literário.

A situação que acabamos de descrever provoca que usando o termo "escrita do crioulo" não se possa falar da grafia de uma língua escrita mas antes do registo de uma língua oral. No caso de autores bilingues cuja língua escrita é o português, pode até observar-se uma certa tendência para o uso da variedade mesoletal, isto é, introdução de traços portugueses na tentativa de encontrar uma estrutura de escrita para a língua oral (Duarte 2003: 169-181). Relaciona-se com

7 Cf. as regras ortográficas propostas no Colóquio em (Delgado, 2009: 339-341) e Duarte (2003: 194-203).

8 Cf. a lista das modificações propostas em Duarte (2003: 202-204) e Veiga (2000: 12-15).

9 Cf. as regras ortográficas do ALUPEC em Delgado (2009: 343-366) e Veiga (2000: 15-17). 
isso o perigo de o crioulo perder a sua identidade, o que é um dos argumentos contra o uso da escrita etimológica. Este sistema ortográfico pode originar uma aproximação exagerada do crioulo ao português, tornando-se as diferenças fonético-fonológicas irrelevantes.

O corpus de textos que analisamos registou-se usando o sistema mais tradicional, isto é, a escrita etimológica com uma forte correspondência fonémica ao português. Vejamos os seus traços mais caraterísticos, compartando-os com as modificações do sistema fonológico:

\begin{tabular}{|c|c|c|c|c|}
\hline $\begin{array}{c}\text { Fonema/ } \\
\text { acento }\end{array}$ & $\begin{array}{l}\text { Representação } \\
\text { etimológica }\end{array}$ & $\begin{array}{l}\text { Representação } \\
\text { fonológica }\end{array}$ & $\begin{array}{l}\text { Exemplos } \\
\text { Santiago }\end{array}$ & $\begin{array}{c}\text { Exemplos } \\
\text { São Nicolau }\end{array}$ \\
\hline$[\mathrm{b} / \mathrm{v}]$ & $\begin{array}{l}\mathrm{b} / \mathrm{v} \text { regionalmente } \\
\text { condicionados }\end{array}$ & $\begin{array}{l}\text { b, interfones } \\
\text { sem oposição } \\
\text { distintiva }^{*}\end{array}$ & $\begin{array}{l}\text { noiba, combida, gostaba, } \\
\text { pagaba, vinte, solabanco, } \\
\text { sirvi, bez, labanta, bisti, } \\
\text { estaba, biúbo, bem, barinha, } \\
\text { bira, combersa, raiba, } \\
\text { cabalo, viveba, binha }\end{array}$ & $\begin{array}{l}\text { árve, vez, vaca, estava, } \\
\text { levantá, volta, bocê, bai }\end{array}$ \\
\hline [d] & $\mathrm{dj}$ & $\hat{\jmath}$ ou $d z^{\wedge}$ & $\begin{array}{l}\text { odja, bedja, cidja, midjor, } \\
\text { mudjer, fidjo, dja }\end{array}$ & $\begin{array}{c}\text { am'djor/ amdjor, am'djer } \\
\text { (a’mjer/ a'djer) }\end{array}$ \\
\hline [ə] & $\mathrm{e}$ & não se regista & $\begin{array}{l}\text { di/ de, contenti, denti, } \\
\text { discansado, noti, simenti, } \\
\text { verdadi, sangui }\end{array}$ & inganode, espantóde \\
\hline$[\gamma]$ & g, gu & g & $\begin{array}{l}\text { amigo, arguém/ alguém, } \\
\text { consigui, nunguém }\end{array}$ & $\begin{array}{l}\text { frango, gritá, figueirinha/ } \\
\text { figuilinha, ninguém }\end{array}$ \\
\hline$[\mathrm{k}]$ & $\mathrm{c}, \mathrm{q}(\mathrm{u})$ & $\mathrm{k}$ & $\begin{array}{l}\text { qui/ quê, aquel, cada, } \\
\text { branco, fica, qrê/ qré, } \\
\text { piquinoti, quem, toqui, } \\
\text { porco, saco }\end{array}$ & $\begin{array}{c}\text { daquel, cónde, que, } \\
\text { macoque, creditá, quiser, } \\
\text { porcaria, quexá, piqnin, } \\
\text { sóque }\end{array}$ \\
\hline$[K]$ & $\mathrm{lh} / \mathrm{i}$ & $\hat{\mathrm{I}}$ & - (barudju, odjâ, midjo) & oiá, fóia, páia \\
\hline [n] & $\mathrm{nh}$ & $\mathrm{n}^{\wedge}$ & $\begin{array}{l}\text { padrinho, nhô, dinhêro/ } \\
\text { dinhéro, pánha, } \\
\text { divagarinho, senhor, tinha, } \\
\text { madrinha, caminho }\end{array}$ & $\begin{array}{l}\text { tinha, companhér, nha, } \\
\text { sapatinha, denhér/ } \\
\text { d’nher, pelinha/ pililinha, } \\
\text { manhenta }\end{array}$ \\
\hline [R] & $\mathrm{rr}$ & $\mathrm{r}$ & $\begin{array}{l}\text { burro, còrrê, terreno, arriba, } \\
\text { mòrrê, barril, ferro }\end{array}$ & $\begin{array}{l}\text { corrê, barriga, arriba, burro, } \\
\text { curral, morrê, terra }\end{array}$ \\
\hline$[\mathrm{s}]$ & s, ss, X, c, ç & $\mathrm{s}$ & $\begin{array}{l}\text { sisti, lenço, pensa, xinti, } \\
\text { xinta, fiticera, missa, gossi, } \\
\text { almoça, cussia, passaba, } \\
\text { cabeça, paxenxa, discança }\end{array}$ & $\begin{array}{c}\text { desse, cumeçá, isso, graça, } \\
\text { mostróbe, proximá, xatice, } \\
\text { depressa, céu, cintura }\end{array}$ \\
\hline$\left[\int\right]$ & $\mathrm{ch}, \mathrm{x}, \mathrm{z}$ & $\hat{\mathrm{s}}$ & $\begin{array}{l}\text { quexada, chicote, mexê, } \\
\text { abaxo, dixaba, dibaxo, } \\
\text { chéra/ tchéra }\end{array}$ & $\begin{array}{l}\text { cheie, capaz, aboxe, xatiá, } \\
\text { dexam, xatice, feliz }\end{array}$ \\
\hline
\end{tabular}

* Outros exemplos de interfones podemos encontrar em: dja/ja, odja/oiá ou chéra/tchéra. 


\begin{tabular}{|c|c|c|c|c|}
\hline $\begin{array}{l}\text { Fonema/ } \\
\text { acento }\end{array}$ & $\begin{array}{l}\text { Representação } \\
\text { etimológica }\end{array}$ & $\begin{array}{l}\text { Representação } \\
\text { fonológica }\end{array}$ & $\begin{array}{l}\text { Exemplos } \\
\text { Santiago }\end{array}$ & $\begin{array}{c}\text { Exemplos } \\
\text { São Nicolau }\end{array}$ \\
\hline$[\mathrm{t} f]$ & trígrafo tch & $\hat{c}$ ou t $\hat{s}$ & $\begin{array}{l}\text { tchoma, tchiga, atcha, } \\
\text { tchora, matchadinha, } \\
\text { tchapéu }\end{array}$ & $\begin{array}{l}\text { tchon, tchuque, fetchóde, } \\
\text { tchegá/ tchgá, intchi, } \\
\text { tcherem } \\
\text { tchife, tcheu }\end{array}$ \\
\hline$[\mathrm{z}]$ & $\mathrm{z}, \mathrm{x}, \mathrm{s}$ & $\mathrm{z}$ & $\begin{array}{l}\text { casamento, casa, mesa, } \\
\text { cozido, fazeba }\end{array}$ & $\begin{array}{c}\text { dezel, dezem/ dzem, desatá, } \\
\text { quiser, fazeme, casa }\end{array}$ \\
\hline [3] & j, ge, gi & $\mathrm{z}^{\wedge}$ & $\begin{array}{c}\text { greja, gemê, hoje, laranja, } \\
\text { fugi, longi }\end{array}$ & sujame, ja, gente, onje \\
\hline $\begin{array}{c}\text { acento } \\
\text { circunflexo }\end{array}$ & $\begin{array}{c}\text { fechamento } \\
\text { da vogal }\end{array}$ & palatalização & $\begin{array}{c}\text { sê, flâ, parcê, podê, fazê, } \\
\text { bêbê, crê, pôco }\end{array}$ & $\begin{array}{c}\text { corrê, agôra, fazê, bô, sê, } \\
\text { depôs }\end{array}$ \\
\hline nasalidade & $\begin{array}{c}\text { marcada pelo } \mathrm{n} / \\
\mathrm{m} / \mathrm{til}\end{array}$ & $\begin{array}{l}\text { representada } \\
\text { apenas pelo } n\end{array}$ & $\begin{array}{c}\text { Chibinho, bom, tem, c’um, } \\
\text { arguém, tchon, não, quim, } \\
\text { doém, } \\
\text { antom/ anton, sinão, } \\
\text { condão, também, } \\
\text { armon, nhã, mãe, porton, } \\
\text { passaron }\end{array}$ & $\begin{array}{l}\text { um, Chibim/ Chibin, } \\
\text { sempre, também, tchon/ } \\
\text { tchom, sapatim, gordin, } \\
\text { tem, manhã, senão, criston, } \\
\text { assim, em, embora, irmon, } \\
\text { tamborim, camim, } \\
\text { gatim, sapatim }\end{array}$ \\
\hline
\end{tabular}

Os linguistas costumam sublinhar que as melhores escritas visam uma excelente transparência entre sinais pertinentes da língua e os sinais gráficos (Doneux 2000: 150-151). O sistema etimológico, apesar de ser constantemente usado, é alvo de alguma crítica. Os defensores dos outros sistemas de escrita sublinham a sua inclinação regionalista, escassa sistematicidade, falta de economia e sobrecarga de acentos, pois para um mesmo som usam-se vários grafemas (a relação fonema-grafema não é unívoca) e os acentos gráficos complicam a grafia natural. Analisando os nossos exemplos, podemos observar, de facto, uma inclinação regionalista no uso dos fonemas [b/v] (prevalência do [b] em Santiago e do [v] em São Nicolau ${ }^{10}$ ) ou hesitações ortográficas na representação do mesmo som, que no caso de uma única autora ressaltam a falta de sistematicidade da escrita, ou seja, o seu caráter aleatório, muito possível de se produzir quando se utiliza uma escrita histórica. As representações múltiplas do mesmo fonema, por exemplo do $[\mathrm{k}]$ ou $[\gamma]$, dependem do contexto fonológico e os sons encontram-se em distribuição complementar (Doneux 2000: 149). No entanto, Doneux (idem: 151) afirma que não há línguas difíceis de transcrever. A escolha a fazer depende do domínio sociolinguístico, sociológico e mesmo político. Na situação de plurifonologia ou pluriortografia, é preciso aceitar uma parte do aleatório. No entanto, o que se costuma pôr em relevo e o que se pode observar nos nossos exemplos é que existe, por razões históricas, uma proximidade fonética relativamente grande entre as ilhas de Santiago e São Nicolau.

10 Cf. Veiga (1995: 44) e Delgado (2009: 206): O som [v] não é frequente nos sistemas das línguas da Costa Ocidental africana. Também o português quinhentista e alguma dialetologia portuguesa, sobretudo os grupos do Norte de Portugal, costumam trocar o [v] por [b]. Daí que o [v] tenha pouco rendimento funcional na variante de Santiago (usa-se apenas nas palavras recentes ou eruditas, como televisão). As ilhas do Barlavento foram povoadas mais tarde $\mathrm{e}$ provavelmente por isso nota-se uma maior influência do português do século XVIII e maior rendimento do som [v] que se pronuncia da mesma forma como em Portugal, à exceção de São Nicolau. 


\section{Comparação dos traços morfossintáticos e lexicais do crioulo do Barlavento e Sotavento}

Na definição de Saussure (apud Delgado 2009: 39), a língua não é uma função do sujeito, mas sim um produto social utilizado pelo sujeito falante ${ }^{11}$. Por conseguinte, analisando a sua formação temos de tomar em consideração um vasto leque de fatores sociais, culturais e históricos, tanto endógenos como exógenos. No caso do crioulo de Cabo Verde, as circunstâncias que influenciaram a formação e causaram a diversificação linguística entre as ilhas são as seguintes (Delgado 2009: passim) ${ }^{12}$ :

- O povoamento das ilhas, realizado em épocas diferentes, fez com que os sistemas linguísticos se formassem de maneira distinta nas diversas regiões do país. A data mais provável do início do povoamento da ilha de Santiago é o ano de 1462. No entanto, devido ao fenómeno de insularidade, as comunidades do Barlavento e do Sotavento ficaram isoladas durante muito tempo. Analisando as divergências existentes entre os sistemas linguísticos das ilhas, os linguistas têm formulado várias teorias acerca do crioulo cabo-verdiano como um sistema único, dois sistemas caraterísticos para cada grupo de ilhas ou um conjunto de muitos sistemas independentes. Hoje em dia, aceita-se a hipótese da existência de duas grandes variedades (dialetos ${ }^{13}$ ) do crioulo: a do Sotavento (formada nas ilhas de Santiago e Fogo após o primeiro povoamento) e a do Barlavento (conhecida como a variante do Mindelo) que começou a formar-se só no século XIX, com forte influência do português europeu, depois do povoamento das ilhas de Santo Antão e São Nicolau ${ }^{14}$.

$11[\ldots]$ a língua é um conjunto de sinais vocálicos, registados por escrito ou não, por uma comunidade para exprimir o seu pensamento. [...] Sendo resultado de uma necessidade de comunicação, entendemos que ela é um produto, um património cultural, um elemento de identidade de uma nação, um fator de coesão social (Delgado 2009: 45). Delgado (idem: 132) defende, portanto, a tese sociogenética da formação das variedades do crioulo cabo-verdiano. Cf. também as palavras de Aldónio Gomes e Fernanda Cavacas (apud Delgado 2009: 190): “O léxico é ao mesmo tempo o primeiro retrato da realidade não-linguística e o cofre do saber linguístico duma comunidade [...]. O tempo marca as palavras, elas evoluem e adaptam-se às comunidades".

12 Theodora Bynon (apud Delgado 2009: 144) alerta que "a realidade linguística nunca é completamente homogénea: a distância geográfica, a estratificação social e os diferentes graus de formalismo das ocasiões de comunicação são fatores de variação, tanto no discurso de diferentes indivíduos, como no de um mesmo indivíduo". No nosso trabalho, concentramo-nos na diversificação diatópica mas achamos muito interessante a diversificação diastrática que abrange o crioulo basiletal, o crioulo aportuguesado, o português acrioulado, o português cabo-verdiano e o europeu.

13 Sendo o dialeto definido como "variedade de uma língua com algumas particularidades, de acordo com a região e com os utentes/utilizadores dessa mesma língua regional, particularidades que são manifestadas através, fundamentalmente, da fonética e do léxico. O meio envolvente, o nível cultural dos indivíduos, a condição económica dos utilizadores são, entre outros, os fatores que determinam essas particularidades" (Delgado 2009: 145). Como não foram os portugueses que deram origem ao crioulo ao comunicarem entre si, este não pode ser considerado como um dialeto do português, termo simplista que funcionou na linguística durante muitos anos.

14 As ilhas de Boavista, Santo Antão e São Nicolau começaram a ser povoadas provavelmente nos princípios do século XVII e a ilha de São Vicente só em 1794. A estabilização da variante do Barlavento deu-se a partir da estabilização da variante do Mindelo, em 1875. (Delgado 2009: 104, 137). Dulce Almada Duarte (1998) defende que, apesar da variação dialetal, o crioulo é uma língua com unidade suficiente para que haja comunicação entre os falantes das diferentes ilhas e Manuel Veiga (1995) constata que “[...] a nível de estrutura profunda, existe um único Crioulo, razão por que há uma intercompreensão razoável desde as ilhas mais ao Norte (Barlavento) até às ilhas mais ao Sul (Sotavento). [...] não se pode falar de nove crioulos em Cabo Verde, mas sim de um único código que se atualiza, na estrutura de superfície, 
- Interferências entre as línguas faladas pelos escravos ${ }^{15}$ e os dialetos dos colonos. $\mathrm{O}$ crioulo cabo-verdiano formou-se no contexto multilingue, de diversidade de etnias, cada uma portadora da sua língua, permanecendo a necessidade de comunicação. Os colonos brancos começaram a fixar-se no arquipélago por decreto régio de 1472. Estima-se que um século mais tarde a nova língua já estava bastante bem consolidada (Delgado 2009: 99). A ilha de Santiago foi povoada com escravos oriundos da costa ocidental africana e com colonos do norte de Portugal. A fraca mobilidade entre as ilhas, provocada pelo isolamento, propiciou a consolidação do seu sistema linguístico. Estima-se que o número de escravos excedia o dos colonos brancos, o que fez com que aqueles tivessem menos contacto com a língua portuguesa. A ilha de São Vicente, por sua vez, foi povoada com habitantes das outras ilhas (por exemplo, de Santiago, com um crioulo já consolidado, e de Santo Antão e São Nicolau), dos Açores e de Portugal. Existem testemunhos escritos de a coroa portuguesa ter enviado muitos degredados, incentivando e insistindo no povoamento desta zona com "cazães brancos" (Delgado 2009: 105-106). Pode-se dizer, então, que o crioulo de Santiago estava na base de formação das variedades das outras ilhas mas que a variante do Barlavento ficou muito mais influenciada pelo português.

- O processo de assemelhar a língua materna a outra de maior prestígio social e mais funcional, ou seja, a chamada descrioulização. Estas transformações podem fazer com que os crioulos, que costumam ser bastante propensos a esse tipo de "morte lenta" (cf. o caso da Índia e Macau), percam a sua autonomia estrutural e lexical, passando a ser uma variedade do português. Assim, os fenómenos de neologismo ${ }^{16}$ e estrangeirismo, resultantes do contacto com outras línguas e outras culturas, fator de desencadeamento de variação linguística, contribuem para alterar a estrutura semântica e lexical do crioulo. Este vai incorporando no seu léxico termos de outras origens, principalmente a europeia, e abandonando muitos termos africanos que lhe serviram de substrato. Dulce Pereira (apud Delgado 2009: 109) defende que este fenómeno começou no século XIX com o povoamento de São Vicente onde muitos termos africanos caíram em desuso devido à generalização do ensino em português e ao desprestígio do crioulo, proibido na administração pública. Obviamente, este processo é, ainda hoje, mais visível nas cidades onde se pode observar um contínuo de variedades diastráticas. Atualmente, as influências mais notáveis, além das portuguesas, são as inglesas e francesas, resultado da abertura do Porto Grande do Mindelo ao mundo, da emigração e do turismo, da globalização e do surgimento das novas tecnologias ${ }^{17}$. A dita realidade, refo-

em diversos dialetos". Só se falaria de vários crioulos no país se não se verificasse a intercompreensão entre os falantes dessa região. A base da formação é um crioulo basiletal dos séculos XV/XVI, do qual nasceram as diferentes variações regionais (Delgado 2009: 140-141). Portanto, pode-se adimitr a existência das duas variantes grandes e os seus respetivos dialetos insulares, sendo todos os sistemas intercompreensíveis.

15 Não se sabe exatamente que línguas africanas tiveram mais peso na formação dos crioulos de Cabo Verde. Alguns linguistas defendem que podiam ser aquelas da etnia jalofa mas os estudos carecem de provas fiáveis (Delgado 2009: 87).

16 Trata-se aqui dos termos que não faziam parte do crioulo basiletal, tendo entrado no léxico cabo-verdiano depois da independência do país, como: partidu/partide, dimokrasia/demokresia, votu/vote, iletoral/ileitoral, dizenvolvimentu/ dezenvolvimente, etc., sendo versões do Sotavento e do Barlavento, respetivamente.

17 Muitos desses vocábulos entraram no crioulo de forma indireta, devido aos contactos com Portugal. Delgado (2009: 118, 122-130) enumera os exemplos como: ó bróda, ó mén, sorê boi, kofebreke, stafe, orkxope, kompiuta, siberkafé, mitinge, garáge, rendivu, bién, savá, mersi boku, suvenir, etc. Outros são traços da presença dos estrangeiros nas ilhas, 
rçada pelo regresso para as ilhas das pessoas formadas no estrangeiro e pelos movimentos migratórios dentro do país, provoca um certo tipo de desdialetização, ou seja, nivelação das diferenças linguísticas entre as ilhas. Na ilha de Santiago mantém-se ainda um certo conservadorismo linguístico, sobretudo nas zonas rurais mais isoladas onde se fala o chamado "crioulo fundo ${ }^{18}$ ".

Resumindo, então, as diferenças entre as duas variedades explicam-se pelos fatores geográficos, pelo esquema e pela época de formação, pelos elementos linguísticos que contribuíram ao seu surgimento (por exemplo, as línguas africanas faladas pelos escravos), pela intensidade do contacto com o português (e com os diferentes dialetos deste falados pelos colonos) e da mobilidade social ${ }^{19}$. Assim, a variante do Sotavento surgiu dos elementos do português dos séculos XV/XVI e das línguas africanas faladas pelos primeiros escravos nas ilhas de Santiago e, poucos anos depois, nas do Fogo, da Brava e do Maio. A variante do Barlavento, por sua vez, é resultado da confluência desse crioulo basiletal de Santiago, levado posteriormente às ilhas de Santo Antão, São Nicolau e Boavista, com o português dos colonos, formada a partir dos finais do século XVIII, na ilha de São Vicente ${ }^{20}$.

Em São Nicolau, a variante de Santiago deixou algumas marcas que ainda se podem observar na sua própria variação dialetal, sobretudo ao nível lexical e fonológico. Há quem constate que o sistema dessa ilha constitui uma interseção entre as variantes do Sotavento e do Barlavento (Delgado 2009: 149).

Do nosso corpus escolhemos as seguintes caraterísticas que nos pareceram as mais representativas:

- A origem da maioria das palavras é portuguesa. O léxico do crioulo cabo-verdiano compõe-se, na sua maioria, dos vocábulos provenientes da língua de superstrato (muitas vezes caídos em desuso em Portugal), dos vocábulos das línguas africanas e os formados no arquipélago devido à necessidade imediata de comunicação. Nos nossos textos, encontramos apenas dois vocábulos que interpretamos como de origem africana. Trata-se da palavra nhenhefa (35) que, julgando pelo contexto, pode fazer referência à boca, focinho ou garganta, e na qual observamos o fenómeno de reduplicação; e da palavra bandoga (35)/ bandoba com o significado de 'estômago'. O número reduzido de vocábulos africanos pode ter a ver também com o idioleto da autora que registou os contos da tradição oral.

confirmada por exemplo pelos apelidos ainda vigentes, como Spencer, Hopffer, Schofield, Frusoni, Bettencourt, Rocheteau, etc. Deste modo, o léxico, que constitui a principal referência cultural de uma comunidade, reflete o hibridismo linguístico e o multiculturalismo da sociedade cabo-verdiana. Baltasar Lopes (apud Duarte 2003: 54) chegou a designar esse processo como "aristocratização vocabular".

18 O “crioulo fundo" corresponde à versão basiletal; o chamado "crioulo leve", típico da ilha de São Vicente, à versão acroletal, mais aportuguesada. Além disso, o processo de descrioulização praticamente não atinge o crioulo dos falantes monolingues (Duarte 2003: 16).

19 A intercompreensão entre alguns setores da sociedade provenientes de diferentes ilhas era mais difícil até meados da década de 80, época depois da qual aumentou notavelmente a mobilidade social e o desenvolvimento industrial e tecnológico (Delgado 2009: 162-163).

20 Cf. A opinião de Joaquim Vieira Botelho da Costa (apud Delgado 2009: 151): “Na ilha de São Vicente não há linguagem ou, como se diz, crioulo próprio, fala-se o crioulo de todas as ilhas". 
- A categoria de sexo não é funcional, tanto para os substantivos como para os adjetivos. Não há rigor na concordância do género, as suas marcas não são atualizadas com a mesma frequência e ocorrência como no português (1). Como efeito do processo de descrioulização, nos meios urbanos podem observar-se mudanças na flexão do género (ex. decalque da estrutura do português - 2):

\begin{tabular}{|c|c|}
\hline Santiago & São Nicolau \\
\hline 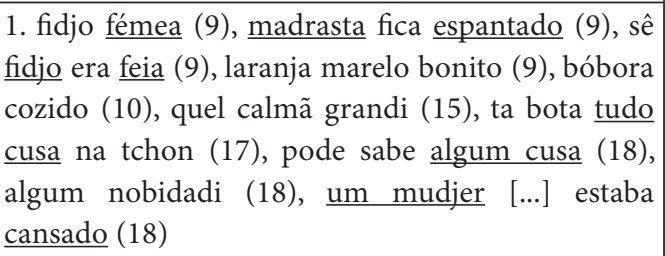 & $\begin{array}{l}\text { 1. aquel figueirinha (20), tude bos gente (20), el } \\
\text { tmá aquel pele (21), rebera sec (30), ramo sec (31), } \\
\text { barriga de vaca é fetchóde ( } 34)\end{array}$ \\
\hline $\begin{array}{l}\text { 2. nha bedja fiticera (9), nha fidja é brancona (10), } \\
\text { sê fidja, nhã princésa (15) }\end{array}$ & \\
\hline
\end{tabular}

- O artigo definido não existe, o indefinido limita-se às formas masculinas (1). Às vezes, o artigo substitui-se pelo demonstrativo (2):

\begin{tabular}{|c|c|}
\hline Santiago & São Nicolau \\
\hline $\begin{array}{l}\text { 1. um mudjer }(9,18) \text {, fumo preto moda um néboa } \\
\text { (10), ta busca um pessoa (18) } \\
\text { 2. [...] quel mudjer ta tinha na canto di casa, mâ } \\
\text { aquel barril ta papiaba co sê ama }(15) \text {, aquel ideia } \\
\text { di Chibinho (26) }\end{array}$ & $\begin{array}{l}\text { 1. c'mé num figuilinha (20), el intchi bolse de figue } \\
\text { (20), um porta (20), um dentada (21), um banda } \\
\text { (21), um am'djer (30), um vez (30), barriga dum } \\
\underline{\text { vaca }(34)} \\
\text { 2. dôs bá pa aquel figueirinha (20), maride daquel } \\
\underline{\text { a'mjer (30), raiz daquel árvre (64), raiz desse árvre }} \\
\text { (64) }\end{array}$ \\
\hline
\end{tabular}

- O diminutivo aparece com bastante frequência como marca do espírito de morabeza, mas também do desprezo (não se registaram casos deste uso):

\begin{tabular}{|l|l|}
\hline \multicolumn{1}{|c|}{ Santiago } & \multicolumn{1}{|c|}{ São Nicolau } \\
\hline $\begin{array}{l}\text { carragadinho (9), mócinhos (10), matchadinha } \\
\text { (10), chibinho (26), devagarinho (27) }\end{array}$ & $\begin{array}{l}\text { goldin (20), figuilinha (20), pertim (21), pililinha } \\
\text { (21), um laval bem lavadim (21), um ratchinha } \\
\text { (22), gatim (30) }\end{array}$ \\
\hline
\end{tabular}

- Flexão do número: a marca do plural é dada por um determinante que, em alguns casos, leva a desinência (adjetivo de quantidade, um numeral, um pronome, um coletivo) e que antecede o substantivo. Em Santiago, muitas vezes apenas o substantivo é flexionável: 


\begin{tabular}{|c|l|}
\hline \multicolumn{1}{|c|}{ Santiago } & \multicolumn{1}{|c|}{ São Nicolau } \\
\hline$\underline{\text { sete companhia di homi (15), tudo guentis bae (16); }}$ & dôs pau de tambor (21), sês fóia (30); nha mãe, nha \\
$\underline{\underline{\text { sete }} \text { ano, sete memento, } \underline{\text { sete }} \text { repartiçon (16); três }}$ & pae, nhas irmon (34) \\
estera di xerém (17), $\underline{\text { dôs }}$ amigo (26), si nhô qré pon & \\
$\underline{\text { na costa (27), era sete ladron (57) }}$ & \\
\hline
\end{tabular}

- O sistema pronominal (1). Reduplicação do pronome (2). Ênclise dos complementos que não são regidos de preposição (3). Contração de pronomes (4):

\begin{tabular}{|c|}
\hline \\
\hline $\begin{array}{l}\text { 1. bu podê confia na mi, pamó ami quê bu madrinha } \\
\text { (9), sangui real } \underline{\text { mi }} \text { chéra (18), } \underline{\text { in }} \text { ta mandaba (18), } \\
\text { nhô atchaba (18), junto mi (19), fica co sê princésa } \\
\text { (19), é combida pa ser sê padrinho (26), ê incontra } \\
\text { co sê compadre ê flal (26), ca nhô flâ! (26), nha } \\
\text { guenti (26), ma el é ca credita (26), si nhô qrê pan } \\
\text { sirvi nhô di padrinho (26), bae co pé di nho (27), } \\
\text { Sim senhor Ti Lobo, nhô pode fica discansado; tó } \\
\text { qui no tchiga greja in ta tra espóra co plaina (27) }\end{array}$ \\
\hline $\begin{array}{l}\text { 2. ami, in era um prinspi encantado (19), a mi in qre } \\
\text { (19), a nhô cusé qui nhô tem? (26), ami in temqui } \\
\text { casa hoje (27); a nhô, nho flam pam traze porta na } \\
\text { mon (57) }\end{array}$ \\
\hline
\end{tabular}

3. porguntal (9), ta bae soltal (15), nhô prinspi flal (16), tanto princésa rogal quê dixal fica (17), nha dixam discansa um poco (17), mãe de Sol dal comida (17), ê gardicel comida (18), um mudjer qui pidim gasadjo (18), Deus bençoabo nha fidjo (18), é canta tó qui nho Prinspi obil é odjal co lágua ta corre para cara baxo (18), pa el é braçal rijo ta tchora (18), rei respondel (18), pregarl partida (26)

4. dor di denti quim tenê (26)

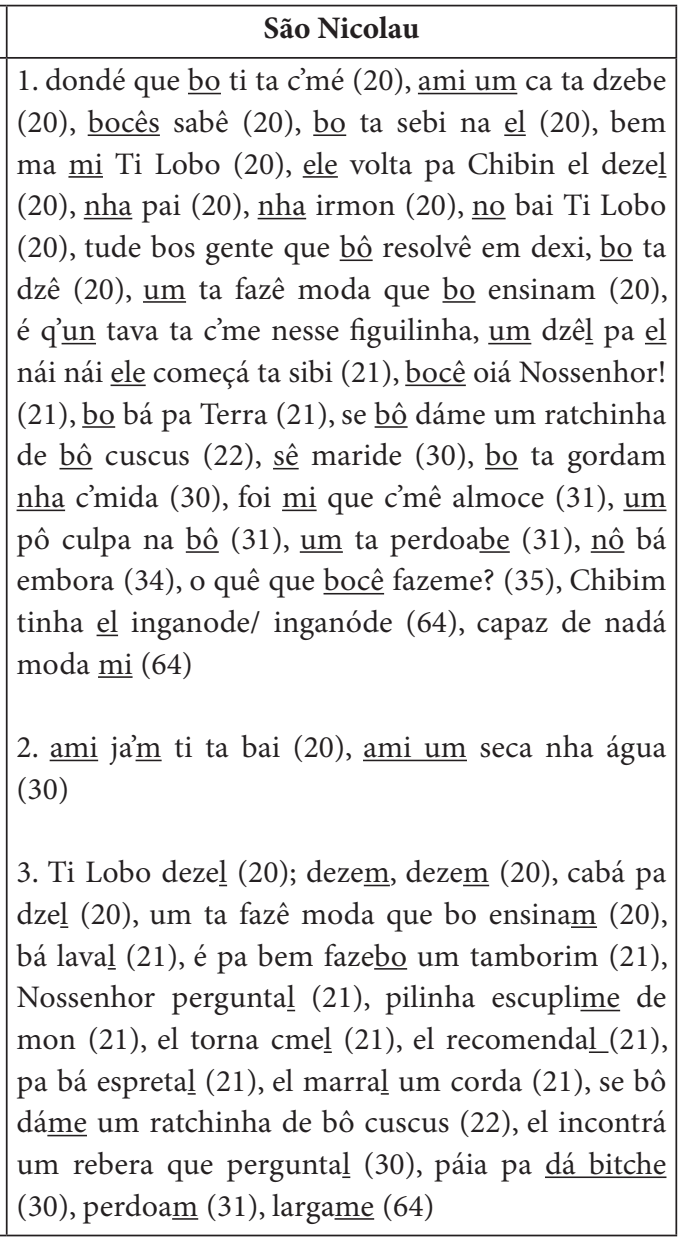

- Os advérbios são importados do paradigma português e desempenham as mesmas funções sintáticas (1) ${ }^{21}$. Aglutinação de alguns advérbios de lugar (2):

21 Cf. $c a<$ nunca, que podia ter também como origem as línguas africanas, já que no sistema banto existe com o mesmo sentido (Baltasar Lopes da Silva apud Delgado 2009: 298). 


\begin{tabular}{|c|c|}
\hline Santiago & São Nicolau \\
\hline $\begin{array}{l}\text { 1. pa da bóbora hoje mé (9), pamodi ê câ gostaba } \\
\text { di nhô prinspi (15), ê bae pol dento dum calmã } \\
\text { grandi (15), tchora té quê ca podê más (16), sempre } \\
\text { ta canta (18), tchiga perto di palácio (18), in temqui } \\
\text { casa hoje (27) }\end{array}$ & $\begin{array}{l}\text { 1. terra ta fcá longe e já é de note (21), lá ca tem } \\
\text { c'mida ( } 30) \text {, aonte bo tinha ága e a hoje não? ( } 30) \text {, } \\
\text { bá pa casa depressa ( } 31 \text { ), Chibim sempre más } \\
\text { esperte (64) }\end{array}$ \\
\hline 2. ta b & \\
\hline
\end{tabular}

- Uso (1) e falta de nexos (2) de coordenação e subordinação:

\begin{tabular}{|l|l|}
\hline \multicolumn{1}{|c|}{ Santiago } & \multicolumn{1}{c|}{ São Nicolau } \\
\hline $\begin{array}{l}\text { 1. É casa c'um homi biúbo qui tinha um fidjo qui } \\
\text { tchomaba Maria (9), era feia moda noti e di odjo } \\
\text { torto (9), bu tem qui fugi sinão bu madrasta ta } \\
\text { matabo (10); ês rema, ês rema, canto nha Bedja } \\
\text { tchiga dja ês estaba longi ta bae (10) }\end{array}$ & $\begin{array}{l}\text { 1. um ta fazê moda que bo ensinam (20), Chibin } \\
\text { dias há quel ca tinha oióde Ti Lobo (20), terra ta fcá } \\
\text { longe é é de note (21), }\end{array}$ \\
$\begin{array}{l}\text { 2. Don Barril dixa sê ama sae di casa (16), ê ca } \\
\text { resisti ê flâs (16), }\end{array}$ & $\begin{array}{l}\text { 2. ele volta pa Chibin el dezel (20), el vrá pa } \\
\text { figueirinha el dzé (20), el tmá aquel pele el bá pa } \\
\text { (21), el panha se gatim el metel dentre de caldera el } \\
\text { tapá (30), maride ovi tude el pensá, el dezê (31), } \\
\text { Chibim vrá pa el dezel (64) }\end{array}$ \\
\hline
\end{tabular}

- Impossibilidade de formação das orações com sujeito oculto ou indeterminado (os pronomes pessoais são obrigatórios devido à ausência da flexão):

\begin{tabular}{|c|c|}
\hline Santiago & São Nicolau \\
\hline 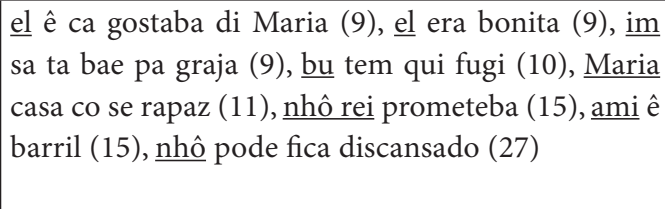 & $\begin{array}{l}\text { bo ti ta c'mé (20), ami um ca ta dzebe (20), bocês sabê } \\
\text { (20), ele volta pa Chibin (20), no bai Ti Lobo (20), } \\
\text { Chibin esperá om bocode (20), um ta fazê moda que } \\
\text { bo ensinam (20), bocê oiá Nossenhor! (21), nô bá } \\
\text { embora (34), o quê que bocê fazeme? (35) }\end{array}$ \\
\hline
\end{tabular}

- Ordem inversa:

\begin{tabular}{|l|l|}
\hline \multicolumn{1}{|c|}{ Santiago } & \multicolumn{1}{c|}{ São Nicolau } \\
\hline pergunta pa sê ama era cusê (15) & Ti Lobo diasá quel ca tinha oióde Chibim (34) \\
\hline
\end{tabular}

- O sistema verbal sem flexão de pessoa, número nem modo (1). Usam-se as formas do infinitivo com apócope do -r, menos ter, vir, ir, estar, ser (2): 


\begin{tabular}{|c|c|}
\hline Santiago & São Nicolau \\
\hline $\begin{array}{l}\text { 1. Si era mudjer, ê ta daba el um saco dinhéro (15), } \\
\text { ca bu fla nunguém (16), in qrê cumê (17), otos ta } \\
\text { máta galinha pa fazê canja (18) }\end{array}$ & $\begin{array}{l}\text { 1. bocês sabê (20), dôs bá pa aquel figueirinha (20), } \\
\text { no bai Ti Lobo (20), se bô dáme um ratchinha de } \\
\text { bô cuscus um ta rapicóbe nha tamblolim (22), nô } \\
\text { bá embora ( } 34 \text { ) }\end{array}$ \\
\hline $\begin{array}{l}\text { 2. bae pánha (10), pa bae liberta princésa (15), na } \\
\text { ca tem ramedi (16), ta bem dum lugar (17), ami pas } \\
\text { bae casamento, tem que ser montado na Ti Lobo } \\
\text { (26), co medo dalgum bitcho bae atacas ( } 57)\end{array}$ & $\begin{array}{l}\text { 2. um onje bem abri porta (20), pa el bá lavá ( } 21) \text {, } \\
\text { hora já tchegá de bo bá pa Terra ( } 21) \text {, um dia saí pa } \\
\text { bá trabaiá ( } 30) \text {, bo tem que ba pedi gatim ( } 31)\end{array}$ \\
\hline
\end{tabular}

- O crioulo é uma língua fortemente aspetual. Ressalta a importância dos advérbios e partículas que marcam as relações de TMA (1). Em Santiago, observa-se o emprego modal da partícula ma que introduz complementos que expressam acontecimentos factuais (2). A mesma partícula em São Nicolau equivale à preposião com (3). Existem exceções que seguem o padrão português, como os verbos ter, estar, ser, vir (4) e, esporadicamente, outros (5):

\begin{tabular}{|c|c|}
\hline Santiago & São Nicolau \\
\hline 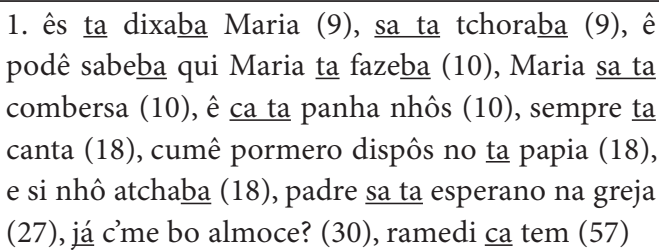 & 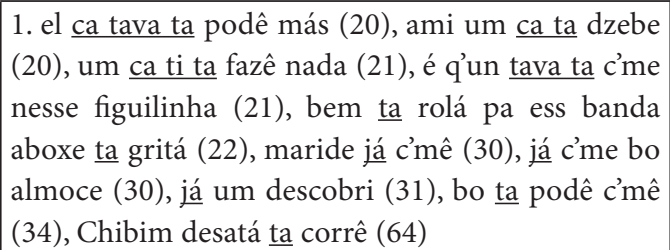 \\
\hline 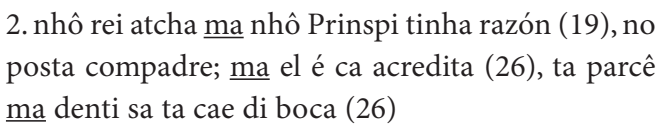 & $\begin{array}{l}\text { 3. bem ma mi Ti Lobo (20), bá falá ma Nossenhor } \\
\text { (21), Ti Lobo má Chibim saí ta passeá (64) }\end{array}$ \\
\hline $\begin{array}{l}\text { 4. estaba longi (10), era fiticera (9), tinha um fidjo } \\
\text { (9), ê tive qui casal co aquel barril (16), aquel barril } \\
\text { era mesmo barril (16), era bento qui sa ta binha } \\
\text { (17), estaba perdido (19)/ ( } \text { sta perdedo) }\end{array}$ & $\begin{array}{l}\text { 4. tem estóde ta c'mé (20), um ca tive culpa (21), Ti } \\
\text { Lobo era dsusperod (22), tinha um am'djer, el era } \\
\text { mute manhenta ( } 30) \text {, aonte bo estava verde ( } 31) \text {, foi } \\
\text { mi que c'mê almoce ( } 31) \text {, tem estóde ta c'mê ( } 34) \text {, } \\
\text { bô pegá foi na raiz desse árvre (64) }\end{array}$ \\
\hline $\begin{array}{l}\text { 5. um passaron tinha robado sê fidja (15), p'é podia } \\
\text { conché caminho (18), paga posta quês tinha feto } \\
\text { (27) }\end{array}$ & $\begin{array}{l}\text { 5. Chibin dias há quel ca tinha oióde Ti Lobo (20), } \\
\text { el ca tinha tchegóde }(22) \text {, se bô quiser manhã cedim } \\
\text { no ta bá (34), cónde bo quiser saí (34), aquel home } \\
\text { pedil desculpa dezinde pa mó el ca tinha oióde } \\
\text { (35), Chibim tinha el inganode/ inganóde (64), el } \\
\text { tinha c'mide (64), el ca sabia nadá (64) }\end{array}$ \\
\hline
\end{tabular}


- Uso específico (1), falta de preposição (2) ou contração com pronomes (3):

\begin{tabular}{|l|l|}
\hline \multicolumn{1}{|c|}{ Santiago } & \multicolumn{1}{c|}{ São Nicolau } \\
\hline $\begin{array}{l}\text { 1. dimoraba di tchiga na greja (26), marido flâ pa } \\
\text { sê mudjer (57) }\end{array}$ & $\begin{array}{l}\text { 1. cabá pa dzel (20), tchgá lá na céu (20), evitá } \\
\text { dalgum xatice (35), el dezê pa Ti Lobo (64), el } \\
\text { resolvê em aproveitá (35) }\end{array}$ \\
$\begin{array}{l}\text { 2. um saco dinhêro (11) / na palácio di nhô rei } \\
\begin{array}{l}\text { (16), fijon pedra co oredjal porco (18), ami pas bae } \\
\text { casamento (26), pa sisti casamento (26) }\end{array}\end{array}$ & $\begin{array}{l}\text { 2. el começá ta laval el dzê assim (21), ta quexá dor } \\
\text { na cadera (30)/ bá quexá de bocê (35), tem estóde } \\
\text { ta c’mê (34), desatá ta corrê (64) }\end{array}$ \\
$\begin{array}{l}\text { 3. má falta poco pan disincanta (16), sae tras di Lua } \\
\text { pé podía conché caminho (18), na punde Chibinho } \\
\text { baba, Ti Lobo ta bae tras d’el (26) }\end{array}$ & $\begin{array}{l}\text { 3. dondé que bo ti ta c'mé (20), pertim dali (21), bo } \\
\text { ta rapicá tambor pám podê sabê c'ma já bo tchegá } \\
\text { (21), pam podê perdoabe (31), pan podê saí (35), } \\
\text { desse manera (35) }\end{array}$ \\
\hline
\end{tabular}

- Negação dupla:

\begin{tabular}{|c|c|}
\hline Santiago & São Nicolau \\
\hline nada ê ca fla (9), ca gosti di ninguém (17) & nunca más ca bô fazê es cosa (31) \\
\hline
\end{tabular}

Na comparação que acabamos de apresentar, pode-se observar que as duas versões têm muitas semelhanças mas também algumas diferenças. Além dos traços ortográficos, incluída a acentuação, ressaltam divergências nas formas pronominais. Contudo, o uso e a colocação dos pronomes são analógicos. Na versão de São Nicolau, reparamos na maior frequência de omissão dos nexos hipotáticos e paratáticos o que faz com que o discurso fique mais livre e mais próximo da oralidade. No sistema verbal observamos bastantes influências do português que, comparando com as gramáticas consultadas, podem ser resultado do idioleto da autora. Todas as divergências descritas mostram que a representação da oralidade na escrita é um processo complicado que ainda precisa de ser estandardizado.

\section{Referências bibliográficas}

Aida, I. (2009). Mam Bia tita Contá Estória na Criol. Mindelo: Gráfica do Mindelo.

Chaves, R. (2000). O passado presente na literatura angolana. Scripta, 3, 6, 245-257.

Delgado, C. A. (2009). Crioulos de base lexical portuguesa como fatores de identidades em África. O caso de Cabo Verde. Praia: Instituto da Biblioteca e do Livro.

Doneux, J. (2000). A propósito do papel dos linguistas... e dos outros na determinação da escrita duma língua. In M. Veiga (org.), I. ${ }^{\circ}$ Colóquio Linguístico sobre o crioulo de Cabo Verde (pp. 143-155). Mindelo: INIC.

Duarte, D. A. (1998). Bilinguismo ou diglossia? Praia: Spleen. 
Elia, S. (1966). A difusão das línguas europeias e a formação das variedades ultramarinas, em particular dos crioulos. Coimbra: FLUC.

Herculano de Carvalho, J. G. (1966). Sobre a natureza dos crioulos e sua significação para a linguística geral. Coimbra: Coimbra Editora.

Kamwangamalu, N. M. (2000). Languages in contact. In V. Webb \& Kembo-Sure (reds.), African Voices. An introduction to the languages and linguistics of Africa (pp. 88-108). Cape Town: Oxford University Press Southern Africa.

Laranjeira, P. (1995). Literaturas africanas de expressão portuguesa. Lisboa: Universidade Aberta.

Leite, A. M. (1998). Oralidades \& escritas nas literaturas africanas. Lisboa: Edições Colibri. . (2003). Literaturas africanas e formulações pós-coloniais. Lisboa: Edições Colibri.

Manana de Sousa, L. (2008). A inversão do código linguístico em Mia Couto. Babilónia, 6, 7, 127-144.

Ndoleriire, O. K. (2000). Cross-cultural communication in Africa. In V. Webb \& Kembo-Sure (reds.), African Voices. An introduction to the languages and linguistics of Africa (pp. 268-285). Cape Town: Oxford University Press Southern Africa.

Postioma, A. da (1968). Filosofia Africana. Luanda: Seminário Arquiepiscopal.

Ribeiro, O. (s.d.). Da ruralidade à cidade: a reinvenção da tradição oral na cultura angolana contemporânea. <http://iberystyka-uw.home.pl/pdf/Dialogos-Lusofonia/Coloquio_ISIiI-UW_26_RIBEIROOrquidea_Da-ruralidade-a-cidade.pdf>

Silva B. (1957). Dialectos portugueses do ultramar. O dialecto crioulo do Cabo Verde. Lisboa: Imprensa Nacional.

Veiga, M. (1982). Diskrison strutural di lingua kabuverdianu. Praia: Institutu kabuverdianu di livru.

- (1995). O crioulo de Cabo Verde: Introdução à gramática. Praia: Instituto Cabo-verdiano do Livro e do Disco.

Webb, V., \& Kembo-Sure. (2000). Language as a problem in Africa. In V. Webb, \& Kembo-Sure (reds.), African Voices. An introduction to the languages and linguistics of Africa (pp. 1-25). Cape Town: Oxford University Press Southern Africa. 